\title{
Fatigue life assessment of a low pressure steam turbine blade during transient resonant conditions using a probabilistic approach
}

\author{
C. Booysen ${ }^{1 *}$, P.S. Heyns ${ }^{1}$, M.P. Hindley ${ }^{2}$, R. Scheepers ${ }^{2}$ \\ ${ }^{1}$ Centre for Asset Integrity Management, Department of Mechanical and Aeronautical Engineering, University \\ of Pretoria, Pretoria, South Africa \\ ${ }^{2}$ Eskom; Research Testing and Development; Johannesburg, South Africa; michael.hindley@eskom.co.za
}

\begin{abstract}
This paper presents a sequential approach used in fatigue life prediction of a low pressure steam turbine blade during resonance conditions encountered during a turbine start-up by incorporating probabilistic principles. Material fatigue properties are determined through experimental testing of used blade material X22CrMoV12-1 along with statistical modelling using regression analysis to interpret the stress-life diagram. A finite element model of a freestanding LP blade is developed using the principle of sub-structuring which enables the vibration characteristics and transient stress response of the blade to be determined for variations in blade damping. Random curve fitting routines are performed on the fatigue and FEM stress data to ensure that the selection of the random variables used in fatigue life calculations is stochastic in nature. The random vectors are selected from a multivariate normal distribution. The use of confidence intervals in the probabilistic fatigue life model works effectively in being able to account for uncertainty in the material fatigue strength parameters and varying stress in the blade root. The predicted fatigue life of the blade is shown to be in good agreement with discrete life modelling results.
\end{abstract}

Key words: Fatigue life, finite element analysis, steam turbine, transient resonant stress, multivariate normal distribution

* Corresponding author: Christopher Booysen; Tel.: +27 11 6295638; fax +27 865563156. Postal address: PO Box 1091, Johannesburg 2000, South Africa. E-mail address: booysech@eskom.co.za. 


\section{Introduction}

Fatigue in low pressure turbine blades has been recognised to be one of the primary causes of steam turbine blade failures worldwide [1-3]. The later stages of the low pressure turbines have been shown to be more susceptible to fatigue damage [2] due to the increased blade lengths resulting in increased stress levels and allowing for a multitude of possible resonances. Various instances of low pressure steam turbine blade failures have been reported in [4-7].

Currently within the power generation industry in South Africa, fatigue cracking and failure of turbine blades is a predicament that faces a large number of its power stations. With increased blade failures and cracking being found in the low pressure blades, this has led to increased attention to structural problems relating to high and low cycle fatigue of the turbine blades.

High cycle fatigue damage occurring during transient blade operation has been identified to be one of the major sources of the recorded low pressure blade failures. The blades experience vibration and resonances at critical speeds $[8,11]$ which produce high dynamic stresses resulting in high cycle fatigue damage accumulation. These dynamic stresses have been shown to be influenced by the source and magnitude of the excitation $[9,10]$ and the damping in the blade $[9,11]$, with approximations of both these variables often required. In the case of a free-standing turbine blade, damping has been shown to be inherently low [1214] which can result in high dynamic stresses at resonance conditions.

Various methods for predicting the fatigue life of turbine blades have been established [1517, 29] along with comparative studies between the various methods [19]. Application of blade life estimation has traditionally been performed using deterministic models which often require overly conservative assumptions. However, given the range of uncertainty in key variables such as material fatigue properties, loading and damping in the blade, the question is then raised about the subjectivity in the selection of these parameters. An alternative approach is to incorporate probabilistic modelling which can eliminate overly conservative assumptions and allow for uncertainty in key variables to be accounted for.

Probabilistic fatigue life modelling techniques are well described throughout literatures [18, 20-22]. Stochastic fatigue damage models have been used to account for the randomness of 
fatigue damage accumulation $[18,20,21]$. The use of a nonlinear damage accumulation rule along with a stochastic $S-N$ curve approach has been shown effect to assess stochastic fatigue life modelling under variable amplitude loading [21].

In this paper the research findings and methodology applied to access the fatigue damage accumulation of a low pressure steam turbine blade during transient resonant operation experienced during a turbine start-up by incorporating probabilistic principles is presented. A database of material fatigue properties and operational blade stresses is determined through experimental materials testing and three-dimensional finite element modelling. From these results, a probabilistic fatigue life model is developed using probability density functions in the form of Gaussian and Weibull distributions along with a generalisation of the univariate normal distribution given by the multivariate normal distribution. This method is a new alterative approach which has yet to be used in probabilistic fatigue life analysis of turbine blades. The probabilistic fatigue life model ensured the effects of variance in the material fatigue strength parameters and the stochastic nature of the transient stress using random variable simulations is accounted for.

\section{Experimental material characterisation}

The test material used in the mechanical and material fatigue properties analysis is the $12 \%$ chromium martensitic stainless steel $\mathrm{X} 22 \mathrm{CrMoV} 12-1$. This material is widely used in manufacturing of low pressure turbine casings and blades due to its superior strength and corrosive properties which are suited for steam turbine environmental conditions. The chemical composition of the material is given in Table 1. It is important to have an accurate determination of the material properties as the values are used as inputs in the development of the finite element blade stress model and for performing fatigue life calculations.

Table 1: Chemical composition of X22CrMoV12-1 sample material

\begin{tabular}{|c|c|c|c|c|c|c|c|c|c|}
\hline \multirow[t]{2}{*}{ Material } & \multicolumn{9}{|c|}{ Chemical Composition [wt \%] } \\
\hline & $\mathrm{C}$ & $\mathrm{Si}$ & $\mathrm{Mn}$ & $\mathrm{P}$ & $\mathrm{S}$ & $\mathrm{Cr}$ & Mo & $\mathrm{Ni}$ & $\mathrm{V}$ \\
\hline Specification & $\begin{array}{l}0.18- \\
0.24\end{array}$ & $\begin{array}{l}0.10- \\
0.50\end{array}$ & $\begin{array}{l}0.30- \\
0.80\end{array}$ & $\leq 0.035$ & $\leq 0.035$ & $\begin{array}{l}11.00- \\
12.50\end{array}$ & $\begin{array}{l}0.80- \\
1.20\end{array}$ & $\begin{array}{l}0.30 \\
0.80\end{array}$ & $\begin{array}{l}0.25- \\
0.35\end{array}$ \\
\hline Sample tested & 0.23 & 0.37 & 0.57 & 0.028 & 0.012 & 12.00 & 0.89 & 0.41 & 0.35 \\
\hline
\end{tabular}




\subsection{Mechanical properties analysis}

Prior to fatigue testing, static tensile tests were conducted to determine the monotonic properties of the blade material at ambient conditions of $22{ }^{\circ} \mathrm{C}$. Tensile test specimens were extracted from the root of the blade in the longitudinal direction. The specimens were designed and manufactured to incorporate a round dumbbell shape with a reduced area section between blended fillets with a diameter of $6.25 \mathrm{~mm}$ (Figure 1a) as per guidelines set out in the BSI standard [23]. Careful consideration was taken in ensuring finishing was maintained in the reduced area section of the test samples. A gauge test length of $25 \mathrm{~mm}$ was required for fitment of a clip gauge extensometer.

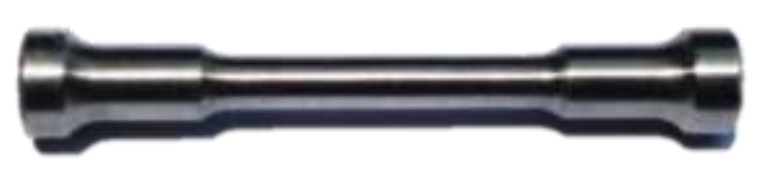

Figure 1a

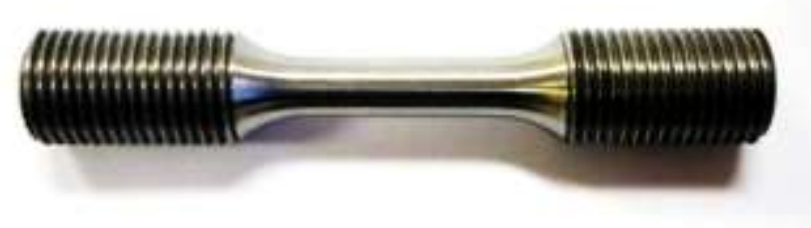

Figure1b

Figure 1: a) Round dumbbell type tensile specimen b) Threaded end fatigue specimen

An Instron 5582 Universal testing machine comprising a $100 \mathrm{kN}$ load frame and dynamic strain gauge extensometer was used to determine the tensile properties of the material. Careful attention was applied in ensuring the gripping axis of the test specimen coincided with the centre line of the heads of the Instron machine, to ensure no bending stresses were introduced.

Testing was carried out at an initial pre-load of $10 \mathrm{MPa}$ at $1.5 \mathrm{~mm} / \mathrm{min}$. Upon reaching the 10 MPa threshold, the strain reading was zeroed. The test run then began at an initial rate 1 (control mode 1- stress state) of $11 \mathrm{MPa} / \mathrm{s}$. After initial material yielding, a rate 2 (control mode 2, strain state) was used which corresponds to a strain rate of $0.005 \mathrm{~s}^{-1}$. During the test, data was captured at $20 \mathrm{~ms}$ and $5 \mathrm{MPa}$ increments. 
The yield strength $\sigma_{y}$ was obtained by using the $0.2 \%$ offset method and the ultimate tensile strength $\sigma_{u}$ was defined as the maximum stress. The elastic modulus $E$ is defined as the slope of the elastic region of the tensile stress-strain curve.

\subsection{Fatigue properties determination}

\subsubsection{High cycle fatigue testing}

Fatigue testing was performed using a multipurpose MTS Landmark static-dynamic testing machine designed on a closed-loop servo-hydraulically controlled system. All tests were carried out under load control as per testing guidelines described by the ASTM E466 [24] for force controlled testing.

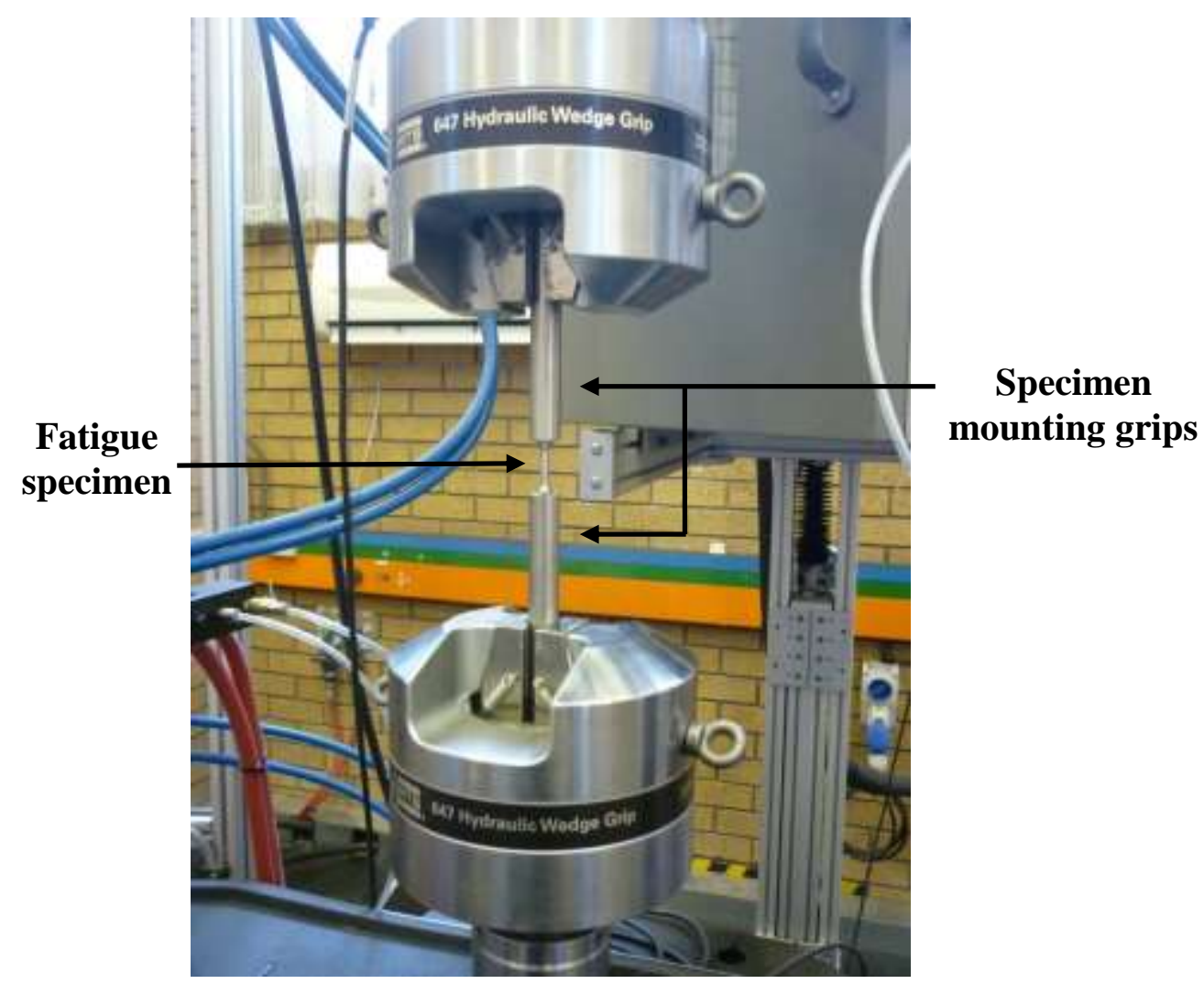

Figure 2: HCF test arrangement and specimen clamping

Fatigue test specimen geometries were designed based on an unnotched specimen with no stress raisers on the test section and included tangentially blended fillets between the test section and the gripping ends [24]. The specimens were designed to best utilise the material available from the root of the blade, taking into account geometrical limitations of the root. An illustration of the fatigue specimen and test setup is shown in Figures $1 \mathrm{~b}$ and 2 . The test specimen has a gauge length of $18 \mathrm{~mm}$ and diameter of $6 \mathrm{~mm}$. The gripping cross-sectional 
area was designed to be at least 1.5 times the test section area. The specimens were polished in the radial direction in order to minimize stress concentration on the gauge area. The effects of residual stresses induced during specimen preparation were not considered in this study.

Due to the fatigue equipment being designed for large scale fatigue testing and the requirement for a sub-sized specimen, specimen mounting grips (Figure 2) were required for axial positioning and securing of the fatigue specimens. A clamping rod design ensured the ends of the fatigue specimen were tightly secured to avoid any potential backlash whilst a dual fastening nut arrangement prevented any additional movement of the clamping rod and fatigue specimen.

The fatigue cycles tested were fully reversed tension-compression with a zero mean stress at a stress ratio, $R=-1$ and tension-tension with a mean stress at a stress ratio, $R=0.1$. A sinusoidal wave shape load input ensured the specimens were subjected to constant amplitude cycling using load control with a cyclic test frequency set at $10 \mathrm{~Hz}$. The failure criterion was defined as complete separation and specimens which failed outside of the gauge test area, be it in the blend fillet radius or at the threaded end were discarded and the results not considered. This ensured the results are consistent with the same mode of failure and to prevent any unnecessary inconsistencies in the scatter of the fatigue data.

\subsubsection{Statistical fatigue data analysis}

When multiple fatigue tests are run at a single stress level there will always be some form of scatter existing in the fatigue lives. This scatter arises from variations that exist from sample to sample such as variations in the material properties, specimen alignment, surface roughness and internal defects to name a few. As a result statistical analysis is required to interpret the $S$ - $N$ diagram.

The $S$ - $N$ relationship of the fatigue test data was approximated using statistical analysis by linear regression modelling as set out by the ASTM E739 [25]. The statistical analysis assumes that the logarithms of the fatigue lives follow a normal distribution and that the variance of the log-life is constant over the entire range of testing. The $S$ - $N$ relationship for the fatigue data is described by a linear model of fatigue from which the statistical $S-N$ curve is developed using the constant amplitude cyclic stress data and resultant fatigue life cycles to 
failure, $N_{f}$. It must be noted that statistical analysis guidelines do not apply for specimens which did not fail and hence these results are not accounted for in the statistical analysis work.

\section{Finite element modelling and analysis}

Finite element modelling involved determining the magnitude and distribution of the blade stresses for simulated operational conditions along with assessing the blades natural frequencies. The biggest challenge involved in modelling a steam turbine blade is in proper selection of the boundary conditions and contact interfacing between the root and the rotor. To ensure accuracy of the finite element model solution, results were validated against measured frequencies and failure investigation results to correlate the crack origin with localised peak stress positions.

\subsection{Finite element model}

A last stage sample blade was used for geometrical scanning to determine the blade topology. The scanned data was converted into a solid model and then imported to the ANSYS finite element program for further modelling and analysis. The geometric model is developed on the principle of sub-structuring whereby an entire turbine row can be modelled using a single sector which is a repetitive piece. The blade model mass is $14.83 \mathrm{~kg}$ excluding the mass of the rotor sector.

The solid model was meshed using higher order three-dimensional 20-node solid elements. The element uses quadratic shape functions and supports stress stiffening as well as large deflection and strain capabilities. Mesh refinement was used in the critical locations of the blade model to ensure accuracy of the solution was maintained. The FEM model (Figure 3) comprises 225009 nodes and 74891 elements. Surface-to-surface contact elements at the landing contact surfaces between the blade root and rotor grooves were specified with quadratic quadrilateral contact and target element formulations used.

\subsection{Steady-state analysis}

Steady state analysis focused on determining the mean stress in the critical location of the blade root and for capturing capture the stress stiffening effects required for dynamic prestress analyses. Linear elastic stress analyses were run considering the effects of the centrifugal forces to determine the steady state stresses. Local yielding was handled using 


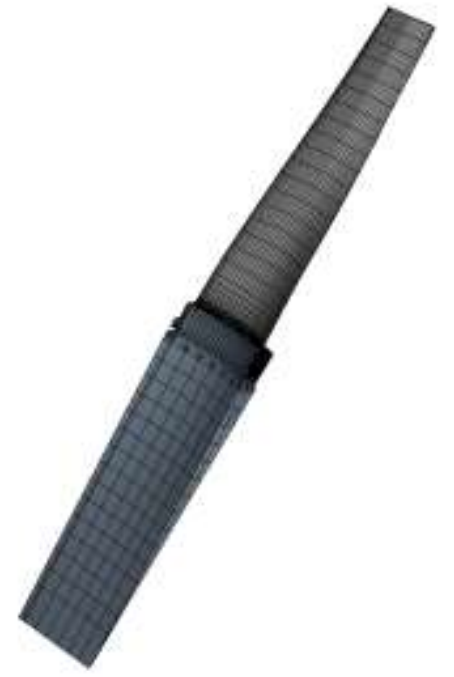

$<$

Figure 3a

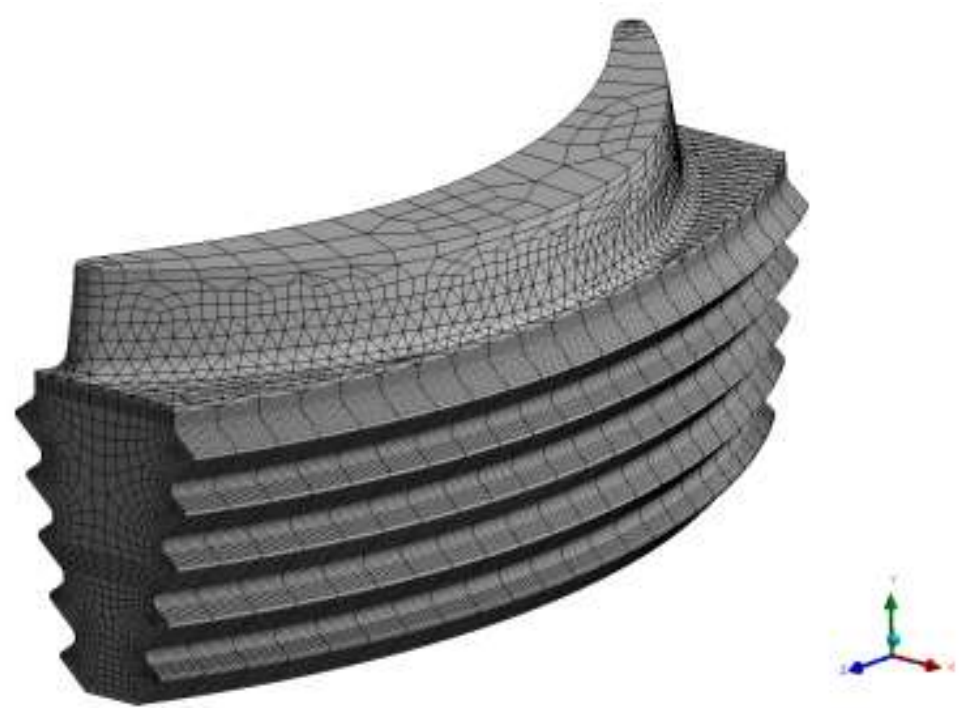

Figure 3b

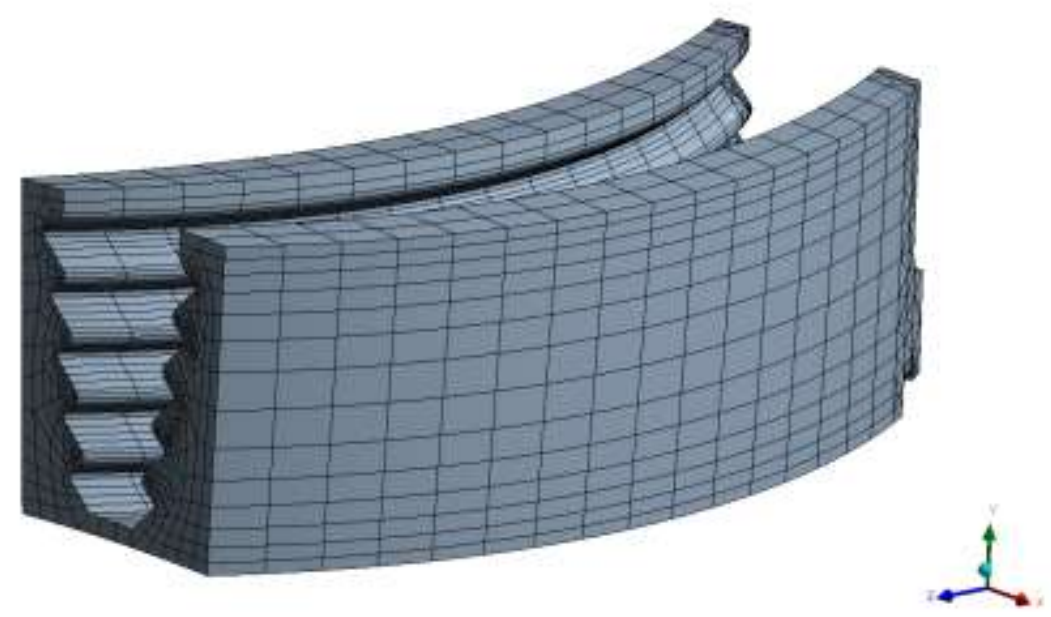

Figure 3c

Figure 3: Finite element blade model 
Neuber's hyperbola and the stress strain curve, with the highest steady state stresses expected to occur in the root attachment of the blade due to the geometric stress concentrations [26].

Using the linear elastic stress results at the peak stress position in the blade root, a hysteresis map for a typical start-stop cycle was calculated using the stabilised cyclic-stress strain curve, stabilised hysteresis loop and Neuber's rule. In order to develop the hysteresis stress map the blade model was loaded to an initial $20 \%$ overspeed (3600 rpm) test, which is typically performed by the OEMs [26]. Due to localised overstressing and plastic deformation caused by the overspeed test, a compressive residual stress is retained at $0 \mathrm{rpm}$. The model is then incrementally run-up to full speed from which the mean stress can be calculated using the localised maximum stress.

Model boundary conditions made use of a cylindrical coordinate system created around the centreline of the rotor shaft to ensure the rotor sector sliced faces aligned to cyclic symmetric requirements. Rotational velocity was applied in the axial direction along the centre of the rotor shaft. Displacement constraints were applied to the rotor shaft face and to an edge of the blade root to prevent axial movement during simulation.

\subsection{Modal analysis}

Modal analysis was used to characteristic the vibration characteristics of the blade in the form of its natural frequencies, mode shapes and the mode participation factors, which are important parameters used in understanding the dynamics of the blade. Using these parameters in the development of the Campbell diagram provided a clearer depiction as to where resonance can be expected to occur during the operation of the turbine blade.

The modal analysis simulations were performed in a pre-stress mode to capture the stress stiffening effects. The pre-stress was generated by conducting an initial steady state static analysis run with an applied centrifugal load varying between 0 to $3300 \mathrm{rpm}$. Being a large last stage blade, the effects of pressure loading on the pre-stressing are expected to be minimal and were thus neglected. What was also taken into account was that the measured blade frequency results were performed under centrifugal loading with no steam conditions and hence the FE model solution needed to be aligned to as measured conditions for validation. The Block Lanczos method was selected as the method of mode extraction using the sparse matrix solver. Higher order disk modes are not expected to play a role because the 
blades are not connected by a lacing wire or wing-band and the blade attachment rotor disk is stiff. Hence, only the first six modes were selected for extraction.

Modal stress results also assisted in providing an indication as to which modes produce maximum stress hot spots that coincide with the crack location positions. This provided an indication as to where synchronous vibration leading to HCF crack initiation could originate from. Considering all three mode peak stresses coincided with the crack location, a simple harmonic response analysis was run using the pressure force calculated in section 3.4.2 in order to identify which mode is most dominant at the area of cracking.

\subsubsection{Frequency verification}

Finite element modelling results were validated against frequency test data supplied by the OEM and by full-scale telemetry results conducted in a balancing pit on the LP turbine rotor. Spin testing involved the LP blades being instrumented with a number of strain gauges that were connected to a telemetry system. The blades were then excited using an artificial source of excitation in the form of an electromagnet. The turbine rotor was initially run-up from 0 to $3300 \mathrm{rpm}$ overspeed conditions from which it was then run-down and the resultant responses from the gauges were measured.

\subsection{Transient structural analysis}

A time-domain transient structural analysis was used to assess the vibration response required to predict the maximum resonant stress whilst passing through a critical speed of assumed resonance. Having a stress load history of the blade root, the number cycles accumulated during the resonance can be calculated and used for fatigue damage calculations. To be able to establish the probabilistic fatigue life methodology for the purpose this research, a single critical speed was used as opposed to a full turbine start-up.

Two key variables needed to be quantified to perform the transient simulations. These are the magnitude of the unsteady excitation pressure to produce resonance and the damping in the blade. To account for variability in blade damping, a numerical damping ratio was selected to follow a normal distribution based on experimental testing results obtained through literature [12-14,26] for similar blade geometries. The damping ratio $\zeta$ was specified to fall between the bounds of $0.08 \%$ to $0.57 \%$ for this large free-standing steam turbine blade. In total twenty four variations in blade damping were considered. 


\subsubsection{Modelling assumptions}

Due to the computational demands of performing a three-dimensional transient structural analysis, a computationally less intensive single blade model was used. The cyclic symmetric model was reduced to a single blade with equivalent displacement constraints at the blade landing faces of the root where contact would occur between the rotor steeple and root serrations. The mode superposition method was used to characterise the dynamic response of the blade to transient excitations. A time-step size of $\Delta t_{i}=0.001 \mathrm{~s}$ was specified to accurately describe the time varying load on the blade. For nonlinear systems, the time step size can have an effect on the accuracy and convergence behaviour of the system.

\subsubsection{Excitation pressure formulation}

The pressure excitation force acting on the blade during a turbine start-up was developed through approximations from the static steam force during partial load conditions which was assumed to be representative of start-up conditions. This was accomplished using Steam Master in conjunction with Steam Pro software to simulate partial load conditions derived from actual operational conditions for this blade. Information from these load conditions enabled the determination of the stage properties required as inputs into steam force calculations. Once having calculated the steam force, the load was applied in the form of a transient pressure to the finite element blade model as formulated in equation 1 . The calculated pressure relates to the excitation amplitude $P_{o}$.

In order to simulate low harmonic excitation, an exciting pressure load representative of nonuniformities in the flow path that would create resonance was formulated. The excitation force $F(\Omega, \mathrm{t})$ was formulated using a varying function expressed by:

$$
F(\Omega, \mathrm{t})=P_{o} \cos (\Omega(t) \cdot t)
$$

with the excitation amplitude which varies sinusoidally with time at a frequency of $\frac{\Omega}{2 \pi} \mathrm{Hz}$ where $\Omega$ is the rotational velocity measured in $\mathrm{rad} / \mathrm{s}$. Excitation occurs during the passing of a critical speed and hence the rotational speed in the time domain is expressed using

$$
\Omega(\mathrm{t})=\Omega_{o}+\alpha t
$$


where $\Omega_{o}$ is the initial rational velocity and the angular acceleration. The excitation frequency $f$ is related to the operational speed using equation 3 .

where $E_{o}$ represents the engine order of interest which for this case is the third engine order. The excitation frequency was calculated at this point to be roughly $100 \mathrm{~Hz}$ based on the modal analysis results at $2000 \mathrm{rpm}$.

\section{Probabilistic fatigue life analysis}

This section presents the development of the probabilistic fatigue life model used to assess the fatigue damage accumulation during a turbine start-up. In order to establish the probabilistic fatigue life model, fatigue damage was initially assessed using a discrete life model from which the modelling assumptions could be developed.

\subsection{Fatigue damage assessment formulation}

Using a rainflow cycle counting algorithm adapted from [27], the FEM transient stress histories are discretised into a set of simple stress blocks and associated cycles for application of Palmgren-Miner's rule in conjunction with Morrow's stress life equation [28]. The number of turbine start-ups required to initiate a fatigue crack is formulated using equation 4

$$
\left[\sum-\right]_{\text {one rep. }}
$$

The life expressed in repetitions to failure is given by $B_{f}$, the number of accumulated cycles is expressed as $N_{i}$ and is determined through the rainflow cycle counting routine performed on the stress histories and $N_{f i}$ is defined as the number of cycles to failure. The number of cycles to failure is originally formulated from Morrows stress-life equation 5. Equation 5 has been extensively used to predict the high cycle fatigue life of LP blades according to [29].

$$
\left(\begin{array}{lll}
\sigma & )
\end{array}\right)(2 \quad)
$$

from which becomes: 


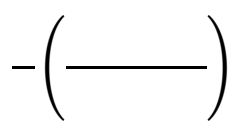

where $\sigma_{a r_{i}}$ is the rainflow counted dynamic stress amplitude and $\sigma_{m}$ represents summation of the mean stress resulting from the centrifugal loading on the blade at the peak stress position in addition to the rainflow counted stress mean $\sigma_{m r_{i}}$.

\subsection{Probabilistic fatigue life modelling}

Uncertainty and variability in the material fatigue strength parameters and the stochastic nature of the transient stress in the blade root due to variability in blade damping is investigated by random variable simulations using a statistical analysis algorithm written in MATLAB.

A simplified approach was adopted to account for the stochastic nature of the transient stress histories. The approach is based on the assumption that the total damage for each transient stress run is caused by the maximum stress obtained from the rainflow counted stress cycle results. This is based on findings obtained from the discrete life analysis. To ensure that the total damage fraction of the entire transient stress signal is maintained, a readjusted cycle count is calculated at the maximum stress value that would give an equivalent damage total as calculated for the combined stress history. This approach enabled all twenty-four transient stress cycle histories to be represented as an equivalent cycles-stress plot of twenty-four points from which curve fitting routines could be employed.

\subsubsection{Random variable curve fitting}

Random curve fitting routines were used to ensure the selection of the random variables used in fatigue life calculations is stochastic in nature. A nonlinear least squares regression analysis using predefined polynomial functions was fitted to the FEM cycle-stress data and experimental $S-N$ fatigue data. Linearity in the $S-N$ fatigue data required a linear polynomial function fit whereas a quadratic polynomial function was fitted to the cycle-stress data. This approach enables all test points to be used simultaneously and the variation estimated over the entire range of tests performed. In conjunction with the fits, the covariance matrix $\Sigma$ was determined and used to obtain the $95 \%$ confidence intervals for the respective data fits. 
Multivariate random curves are then generated through the respective data sets. These random curves make use of a multivariate normal distribution (MVN). The MVN is said to be an abstraction of the univariate normal distribution. It is a distribution for random vectors of correlated variables, each element of which has a univariate normal distribution [30]. The probability density function of the MVN distribution is given by:

$$
\overline{\sqrt{|\Sigma|(}}^{-}
$$

Equation 6 is described by the mean vector $\mu$ and covariance matrix $\Sigma$ which are equivalent to the mean $\mu$ and variance $\sigma^{2}$ parameters of the univariate normal distribution.

Inputs into the probabilistic fatigue life model are based on data obtained through the random variable curve fitting simulations. The statistics of the random variables are described using a statistical distribution function in the form of Weibull, normal or lognormal. Weibull distributions are commonly used in literature in fatigue analysis studies $[21,31]$. The Weibull distribution was also selected on the basis that it can account for data that does not scatter symmetrically about the mean, as in the case of the cycle-stress data where there exists a low percentage of high value peak stress cycles.

The number of random variables chosen was to simulate $1 \times 10^{9}$ simulation runs. This is representative of $1 \times 10^{9}$ turbine start-ups. This made the probabilistic model computationally expensive. In cases where high damage occurred (in the event of an increased mean stress) the number of simulations required was significantly reduced.

\section{Results and discussion}

\subsection{Results of mechanical testing}

Tension test results are summarised in Table 2. A measure of the coefficient of variation $(\mathrm{COV})$ for the yield strength properties is $2.6 \%$. This value is well below the higher end value specified for metals of $7 \%$ [28]. Similarly for the modulus of elasticity and ultimate tensile strength values of $3.91 \%$ and $1.97 \%$ respectively are below the expected $5 \%$. These results indicate superior consistency in the mechanical properties of the blade material as a lower $\mathrm{COV}$ indicates a reduced spread in the results. 
Table 2: Summary of tensile and hardness testing results for X22CrMoV12-1 blade material

\begin{tabular}{lcccc}
\hline \multicolumn{1}{c}{ Specimen ID } & \multicolumn{3}{c}{ Mechanical Properties } \\
& {$[\mathrm{GPa}]$} & {$[\mathrm{MPa}]$} & {$[\mathrm{MPa}]$} & Brinell hardness [HB] \\
\hline 652 & 209.33 & 702.63 & 884.72 & 261 \\
919 & 213.35 & 735.82 & 906.13 & 263 \\
615 & 224.27 & 704.61 & 879.01 & 260 \\
547 & 214.46 & 744.68 & 918.78 & 262 \\
654 & 216.24 & 723.20 & 901.85 & 263 \\
\hline OEM & 205 & $\geq 700$ & $850-1050$ & $252-308$ \\
\hline
\end{tabular}

\subsection{Statistical analysis results on fatigue data}

The resultant $S-N$ curve approximation from the regression analysis, along with the raw fatigue data is graphically shown in the logarithmic scale plot in Figure 4. The regression line is shown to fit both sets of data very well with a high coefficient of determination $\left(R^{2}=96.14\right.$ $\%$ ) calculated for data cycled at $R=-1$. This indicates that $96.14 \%$ of the variability in log is explained by $\sigma_{a}$.

From the results, the fatigue strength coefficient is determined using the stress amplitude intercept at one-half cycle, $\quad=0.5$ and the fatigue strength exponent $b$ from the slope of fitted $S-N$ curve. The calculated fatigue strength coefficient and exponent is listed in Table 3.

Table 3: Experimental fatigue properties

\begin{tabular}{lcc}
\hline Material fatigue properties & $=-1$ & $=0.1$ \\
\hline Fatigue strength coefficient & 1194 & 970 \\
Fatigue strength exponent & -0.077 & -0.087 \\
\hline
\end{tabular}




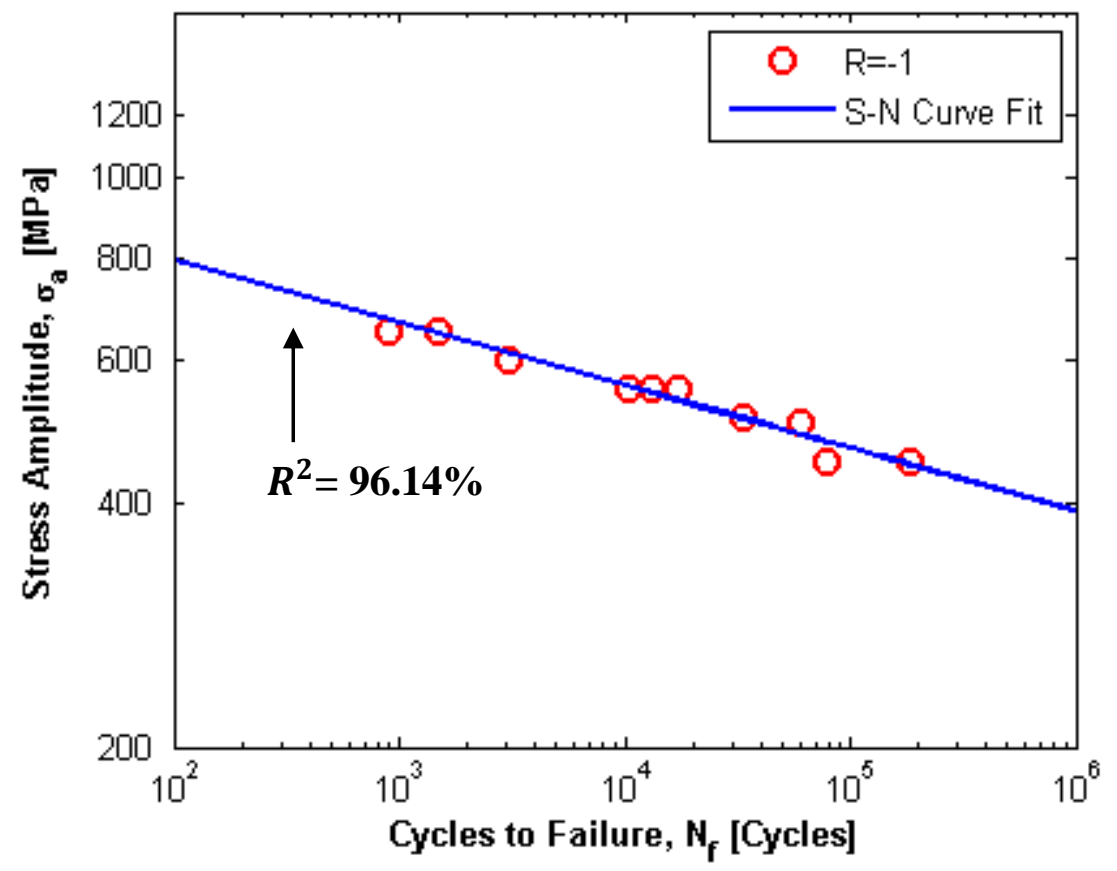

Figure 4a

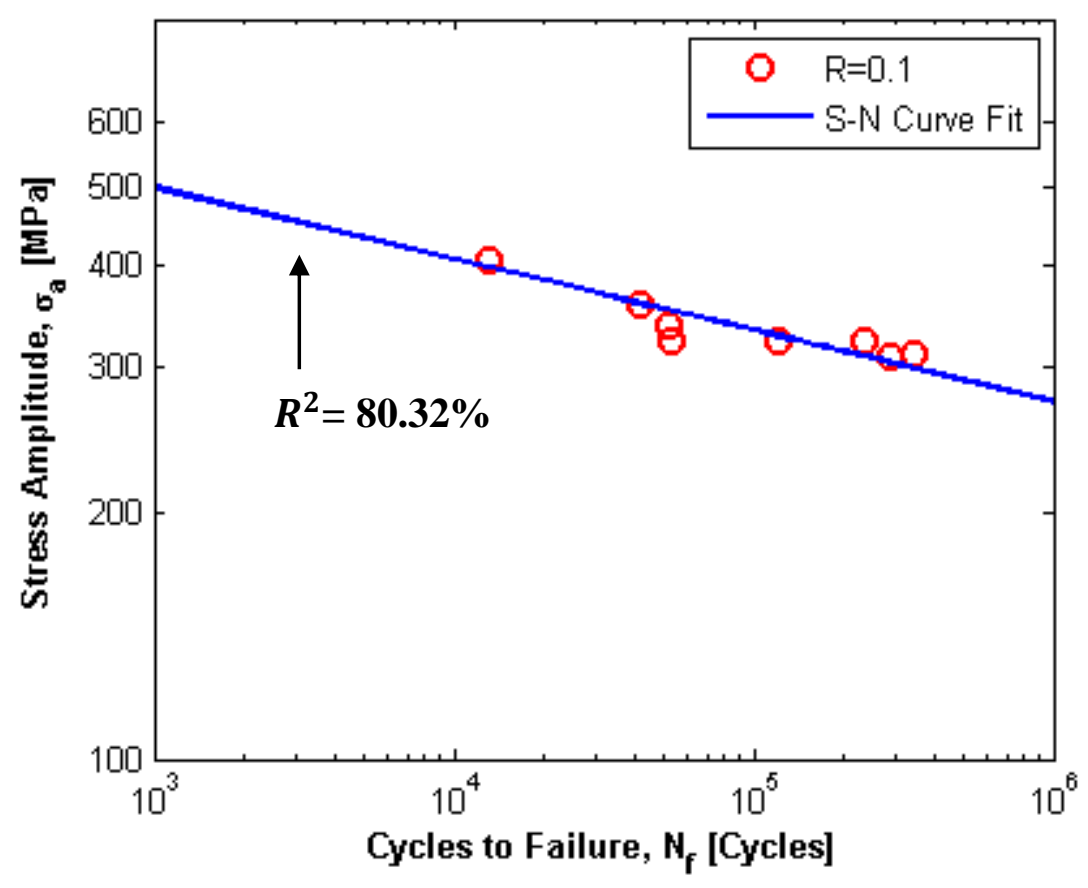

Figure 4b

Figure 4: Regression analysis fit for experimental fatigue data at a) $R=-1$ and $b$ ) $R=0.1$ 


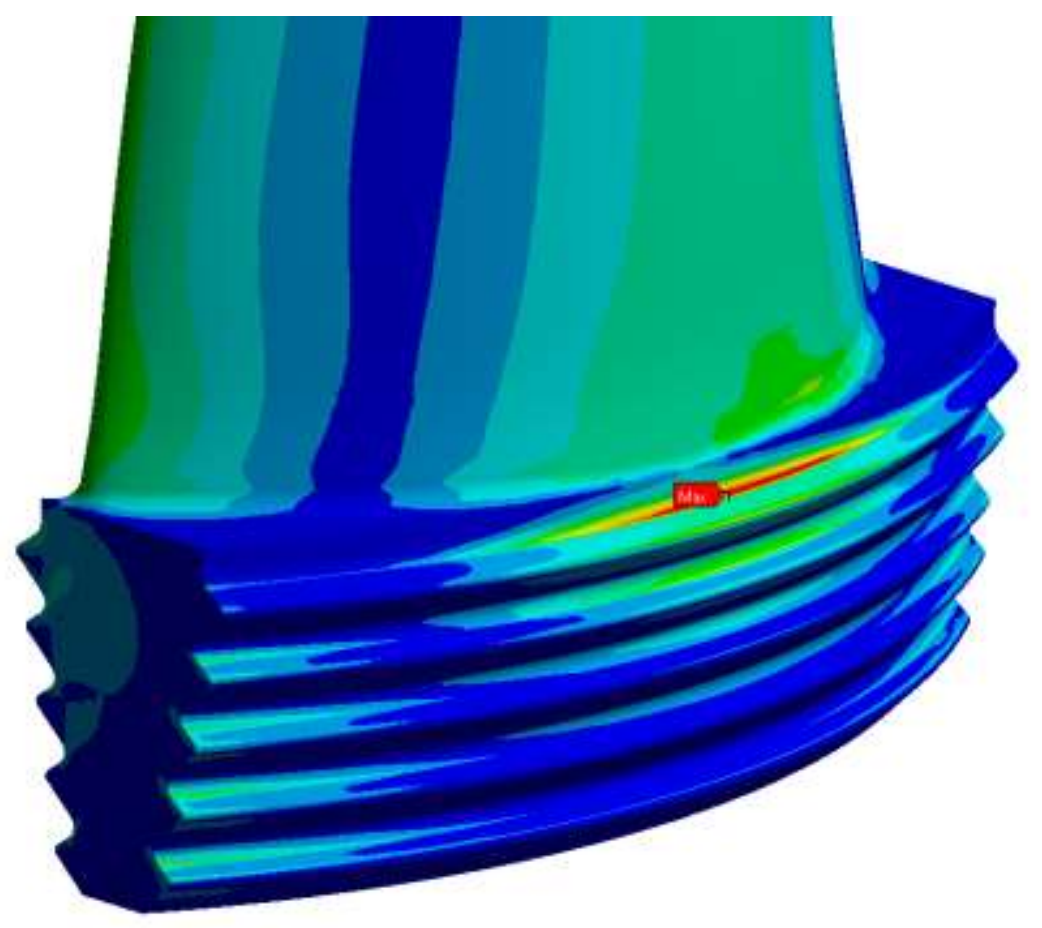

Figure 5a

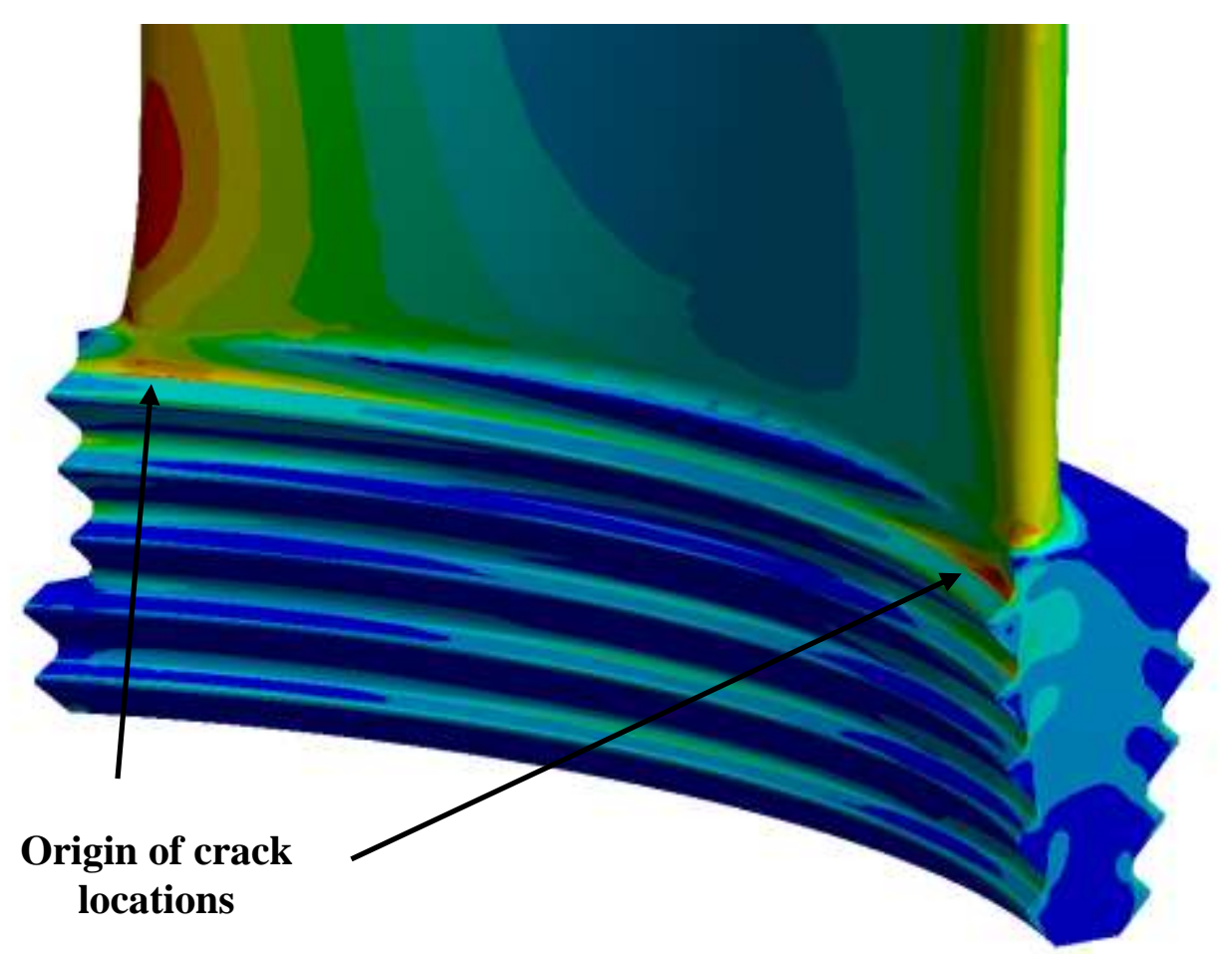

Figure 5b

Figure 5: First mode stress distribution around blade root 


\subsection{Finite element modelling results}

\subsubsection{Steady-state stress analysis}

The maximum elastic stress was found to occur in the upper hook radius which is located adjacent to the contacting surfaces on the convex side of the root. The peak stress position is as depicted in Figures 6 to 9. This position corresponds with cracking initially found from NDE testing performed on these LP blades. The uniaxial state of stress was determined using a coordinate system placed perpendicular to the hook face from which the stress in the normal direction could be determined. At $2000 \mathrm{rpm}$ the mean stress at the critical location in the root was calculated to be $320 \mathrm{MPa}$ and at $3000 \mathrm{rpm}$ the value increased to $580 \mathrm{MPa}$.

\subsubsection{Modal stress distribution in blade root}

Modal equivalent stress distribution results indicated that the first three modes of vibration maximum stress locations (Figure 5) coincide with the position where cracking has been found to occur along the root of the blade. Metallurgical studies indicated that majority of cracking was found to have originated at the convex root side along the top hook serration (Figure 7) which correlates with the hot spot position shown in Figure 6a. To identify which of the modes is most damaging at the crack location, the harmonic response analysis solution was assessed. The frequency response stress distribution was extracted along the convex edge top hook serration and it was found that the most damaging mode of vibration at the position of cracking is the first mode of vibration (tangential mode).

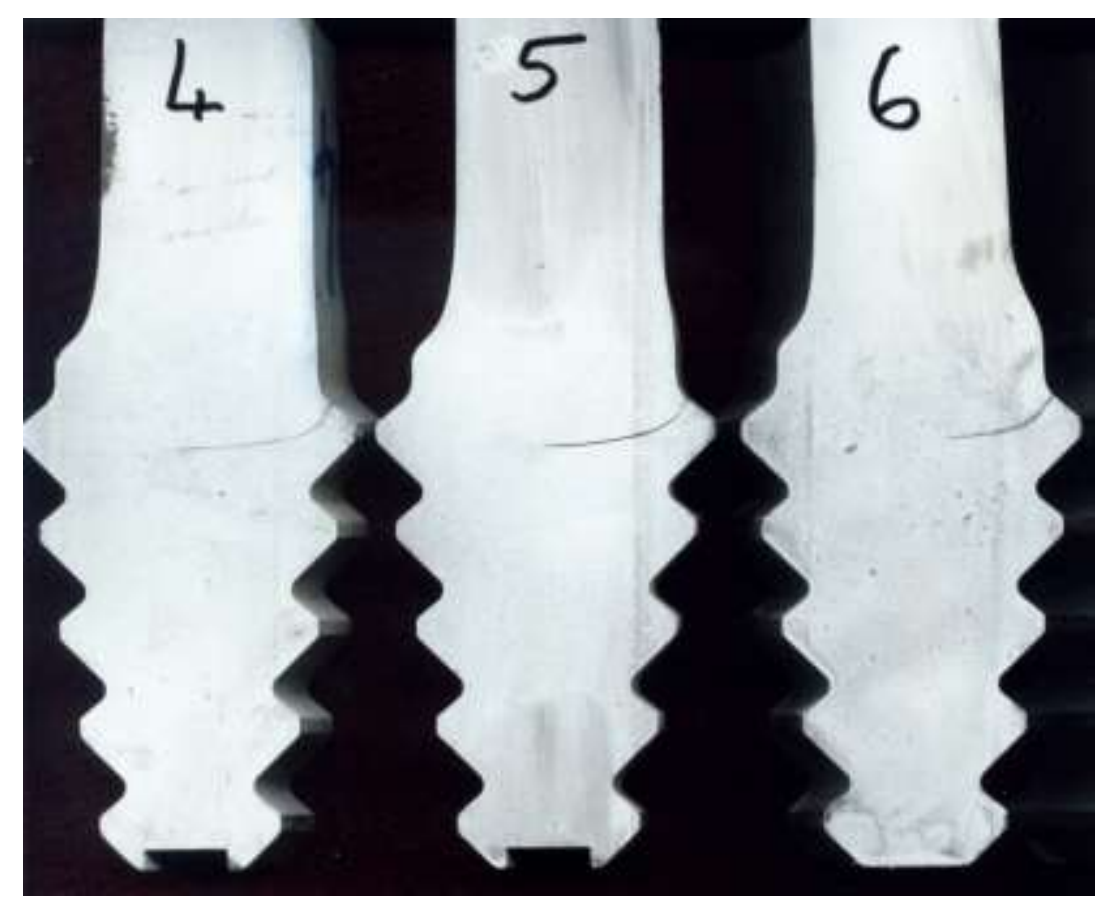

Figure 6: Cross sectional cut through blade root showing crack position and orientation 


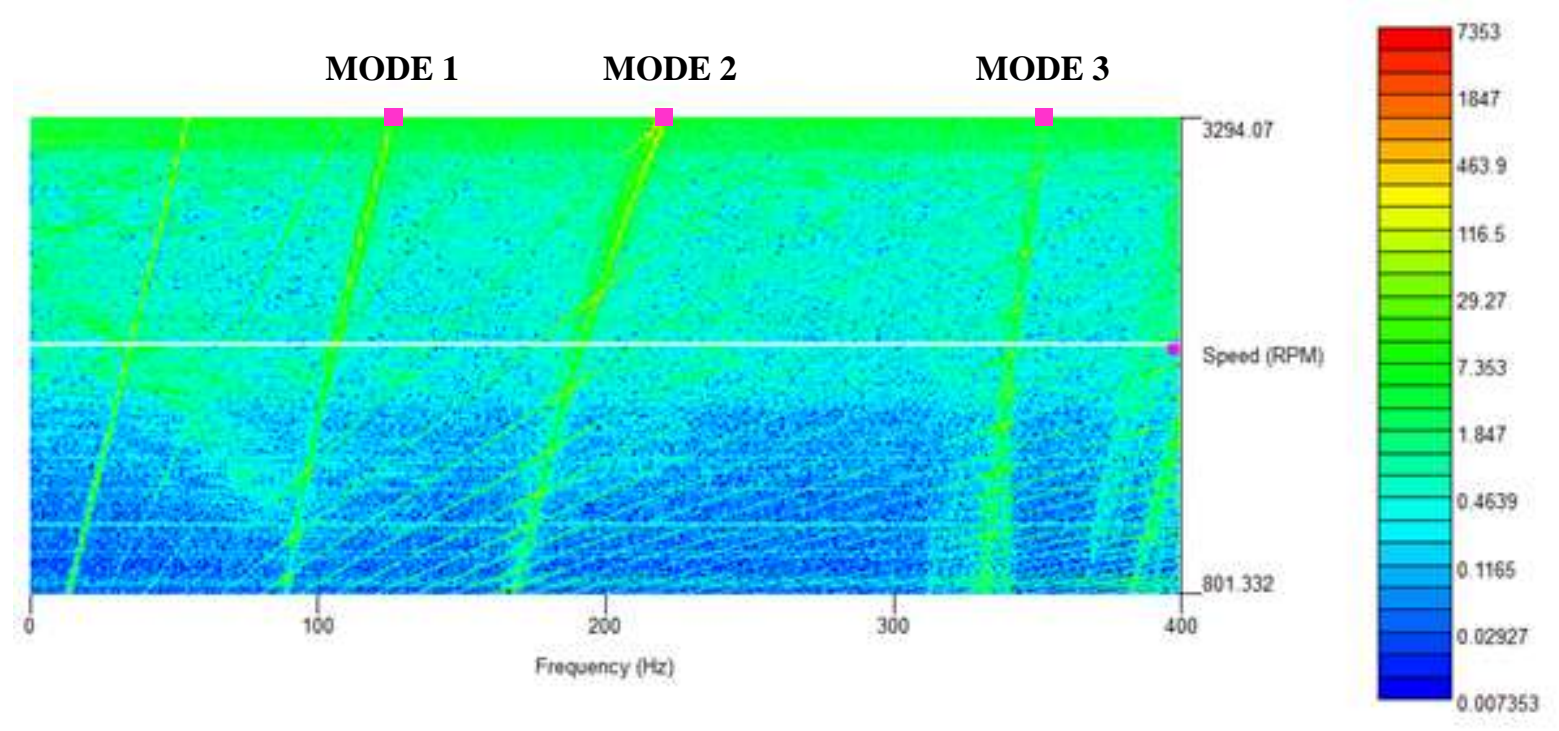

Figure 7: Waterfall display plot of measured blade mode natural frequencies

\subsubsection{Modal and test frequency analysis results}

The measured results from full scale spin testing are displayed in the waterfall display plot shown in Figure 7. The measured blade natural frequencies assisted in validating the finite element blade modelling results.

A comparative plot between the blades natural frequencies versus excitation frequencies as a function of rotational speed for the measured results against the calculated finite element modal analysis results is illustrated in the Campbell diagram plot shown in Figure 8. Using the Campbell diagram, potential resonances existing during a turbine start-up could be identified over the speed range of the machine. A number of potential resonances can occur at positions defined as critical speeds. A critical speed appears when the blades natural frequency is equal to the excitation frequency, which based on Figure 8 occurs when a per revolution harmonic (diagonal line) intersects a mode of vibration curve. 


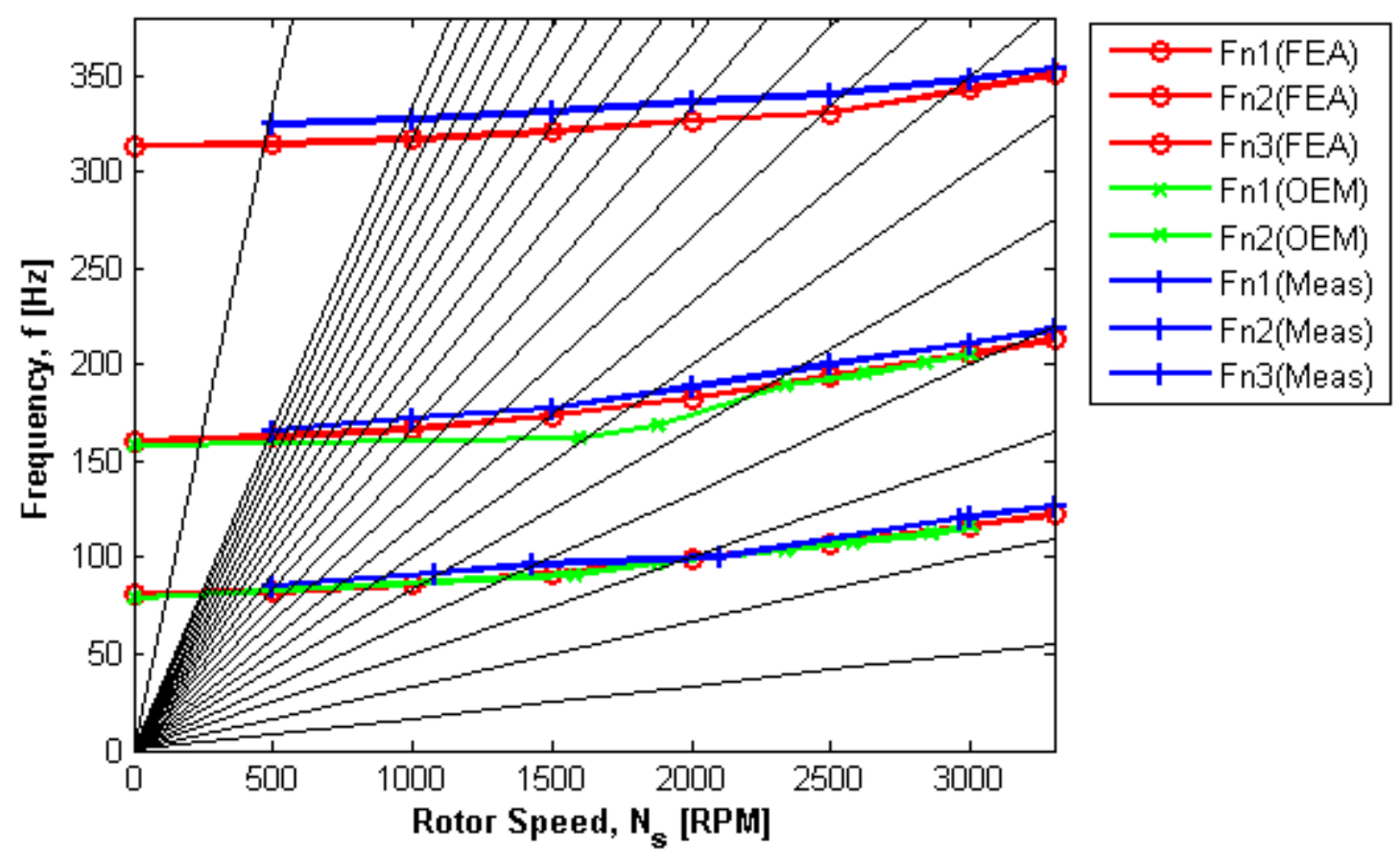

Figure 8: Campbell diagram comparison between calculated and measured blade natural frequencies

From the frequency analysis results, the first six natural frequencies have been calculated to lie below $650 \mathrm{~Hz}$ for the LP blade model and the modes of vibration curves are shown to slant upwards as a result of the centrifugal stiffening effects. It is expected that there exists a slight spread in the results between the calculated and experimental as there is some interaction occurring from the turbine rotor during the measurement process and not all blades are exactly the same, which is not the case in the FEM model where the cyclic symmetry conditions assumes all the blade geometries are the same. Overall the results are in very good agreement.

Having identified the first mode of vibration to be most damaging at the crack location, 2000 rpm was selected to be the critical speed of interest used for this study. This selection is also based on the understanding that the magnitude of excitation decreases with increasing engine order and therefore the lowest engine order interaction with the first mode of vibration would be at $2000 \mathrm{rpm}$ as shown in the Campbell diagram plot.

\subsubsection{Transient resonant stress results}

The stress distribution in the blade root showing the peak dynamic resonant stress location is illustrated in Figure 9. Peak stress is found to occur around the top hook serration on the middle of the convex root side. Mode I cracking was identified to be the driver of cracking in 
the blades based on metallurgical studies. For this reason, a coordinate system was placed at the peak stress position (Figure 9) and orientated perpendicular to the serration face to be able to record the uniaxial state of stress. Transient stress results are extracted from this location.

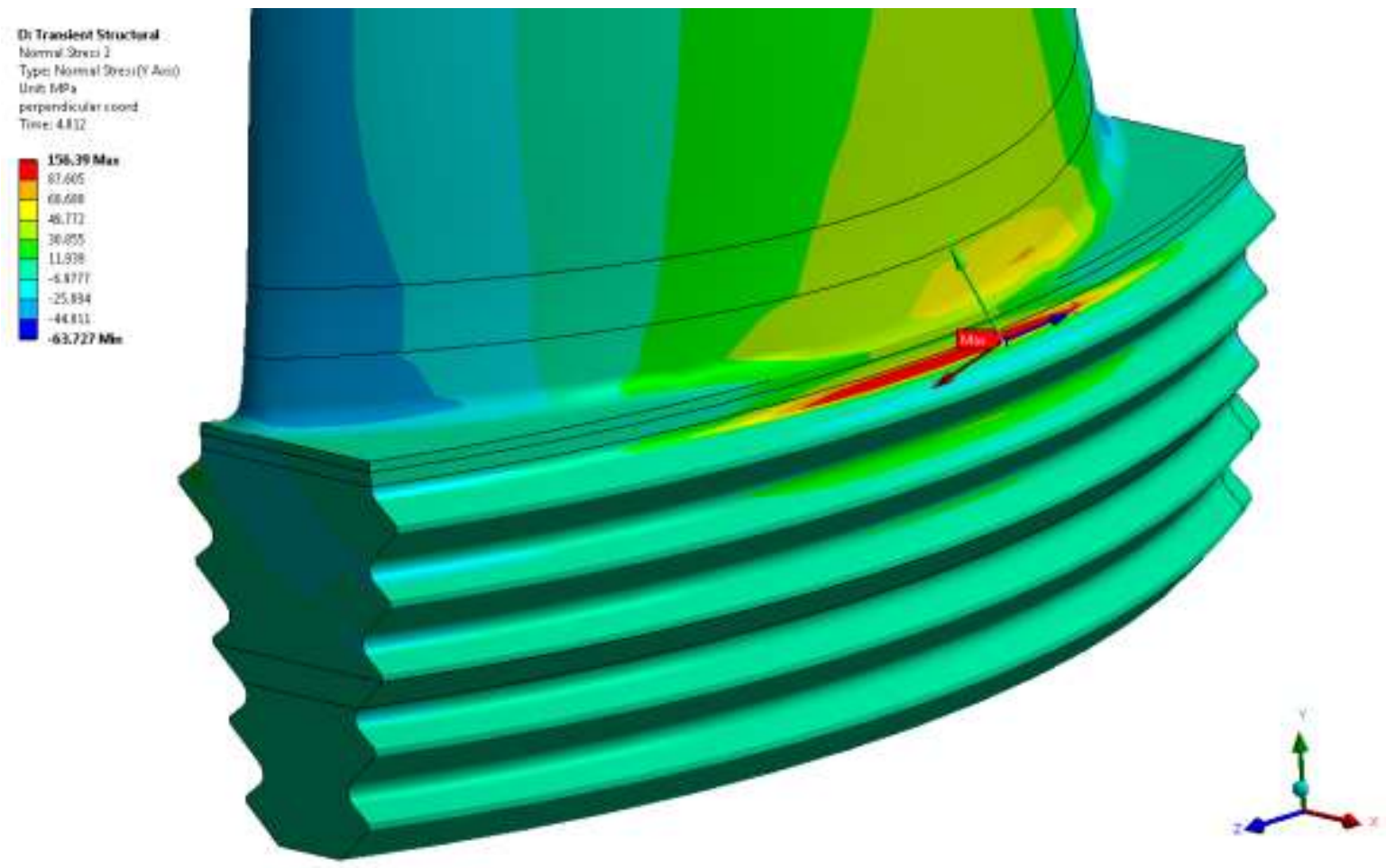

Figure 9 : Stress distribution in blade root during resonance conditions along with the position of the stress measurement coordinate system

Selected transient stress results for variations in the blade damping are shown in Figure 10. The peak stress value at resonance is recorded at $\sim 160 \mathrm{MPa}$ for the average damping ratio of $\sim 0.29 \%$, which is well aligned to findings in literature. EPRI [26] indicates that the dynamic stresses resulting from interaction with the first tangential mode can be in the order of 138 MPa or higher at an assumed resonance condition. Slight variations in the blade damping ratio have been shown to have a significant effect on the stress response at resonance where an increase in the blade damping decreases the amplitude of the response. 


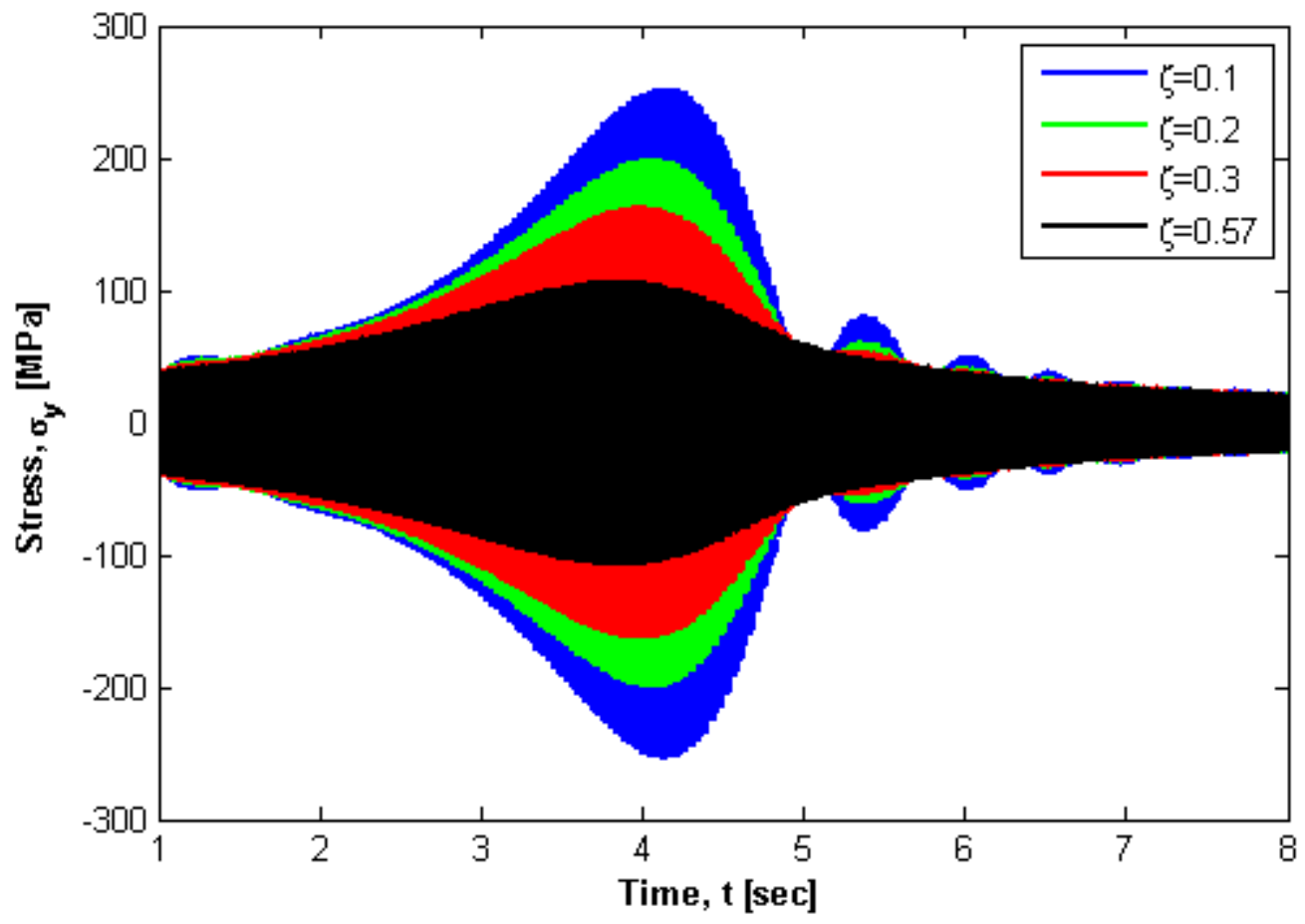

Figure 10 : Transient stress response going through resonance for variations in the blade damping ratio $\sim$

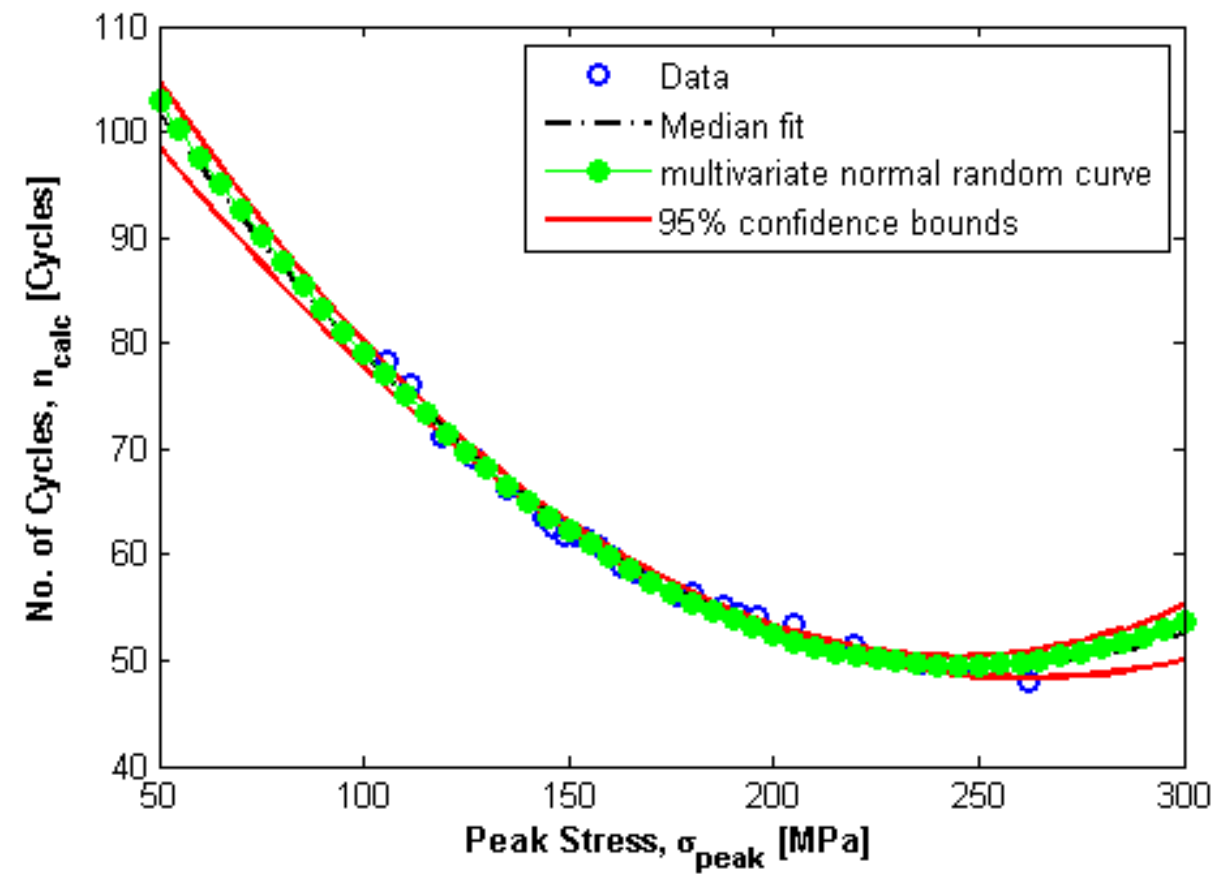

Figure 11 : Multivariate random curve plot through fitted data 


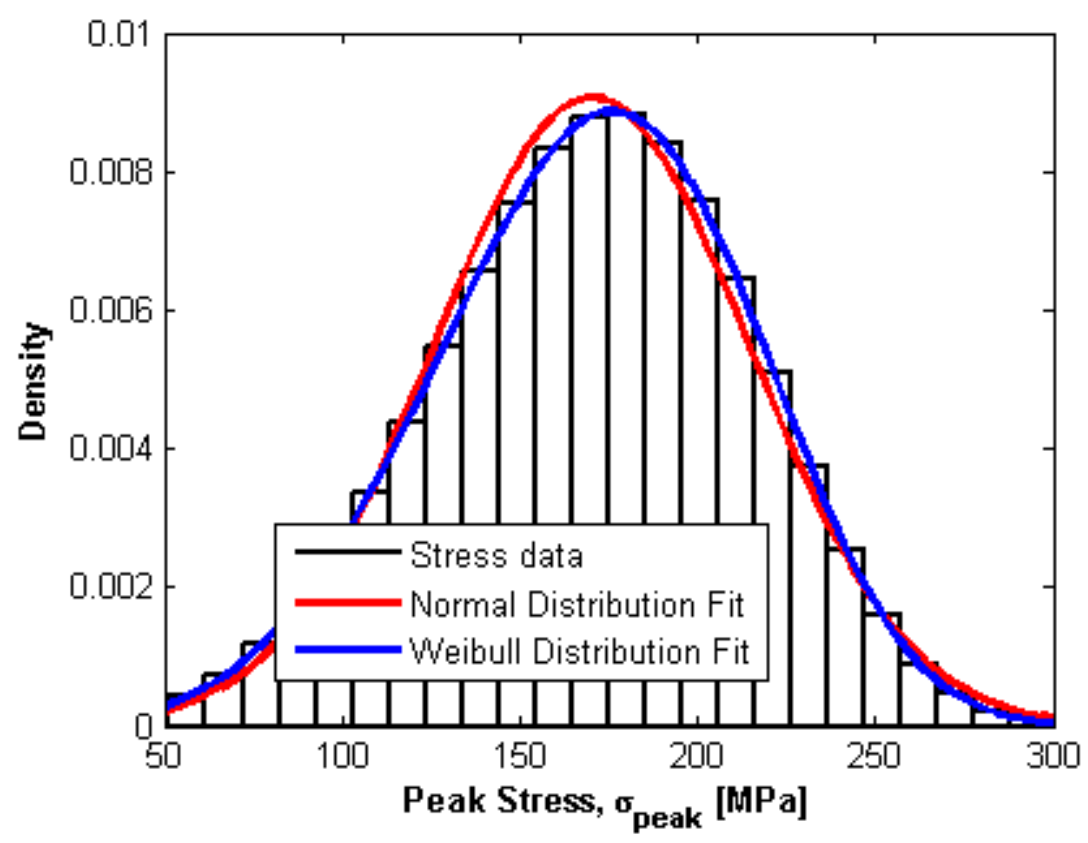

Figure 12a

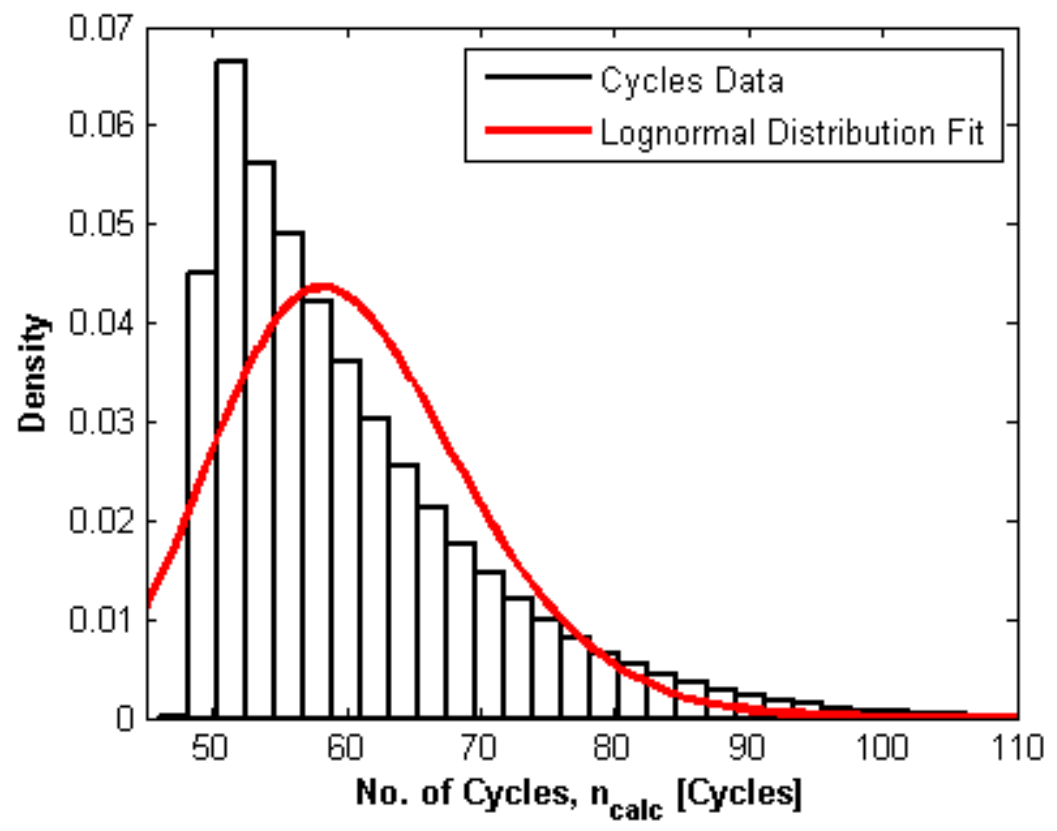

Figure 12b

Figure 12 : Distribution plot of a) peak stress and b) cycles 


\subsection{Fatigue life prediction modelling}

\subsubsection{Statistical distribution model results}

Figure 11 shows a nonlinear least squares fit through the FEM cycle-stress data along with a single random variable analysis run. The confidence bands are shown to be aligned closer to the densely populated data points and grow around sections with less data due to the uncertainty around those points as expected. What must be noted from the curve plots is that the multivariate normal random curves do not follow a uniform path but vary between the respective confidence bound which illustrates the uniqueness in the method.

A summary of the statistical distribution plots of the FEM cycle-stress data and material fatigue data models is shown in Figures 12 and 13. The statistical distribution of the material fatigue properties are well described using a normal distribution as opposed to the distribution describing the peak stress and cycle models as depicted in figure 12. The stress peaks were selected to follow a Weibull distribution to ensure that the high values of peak stress at low levels of damping were accounted for. Due to the stochastic nature of the cycle calculation, the cycles plot is shown to follow a lognormal distribution. The cycle data was expected to be skewed as a majority of the data was located in the low cycle range with a low expectancy of occurrence at high cycles.

\subsubsection{Probabilistic modelling results summary}

The probabilistic fatigue life modelling results are summarised in the distribution plots in Figures 14 and 15. The results represent the number of repetitions, which for this case is turbine start-ups, required to initiate a fatigue crack which was defined as the failure point. It must be noted that the results are calculated based on the fatigue damage accumulation for a single critical speed encountered at $2000 \mathrm{rpm}$. As previously discussed, this critical speed position was identified to be the most damaging and would be used to establish the methodology. A superimposed fit over the data once again indicates a normal distribution fits the data very well.

A comparative study between the discrete life model and probabilistic model results is listed in Table 4. Discrete life modelling results are based on the average damage for the twenty four transient stress histories The results from probabilistic analysis reinforced the results of the discrete life model with a percentage difference in the order of $9 \%$. The results from the 
discrete life model solution are shown to have a low probability of failure when superimposed onto the probabilistic model distribution plot.

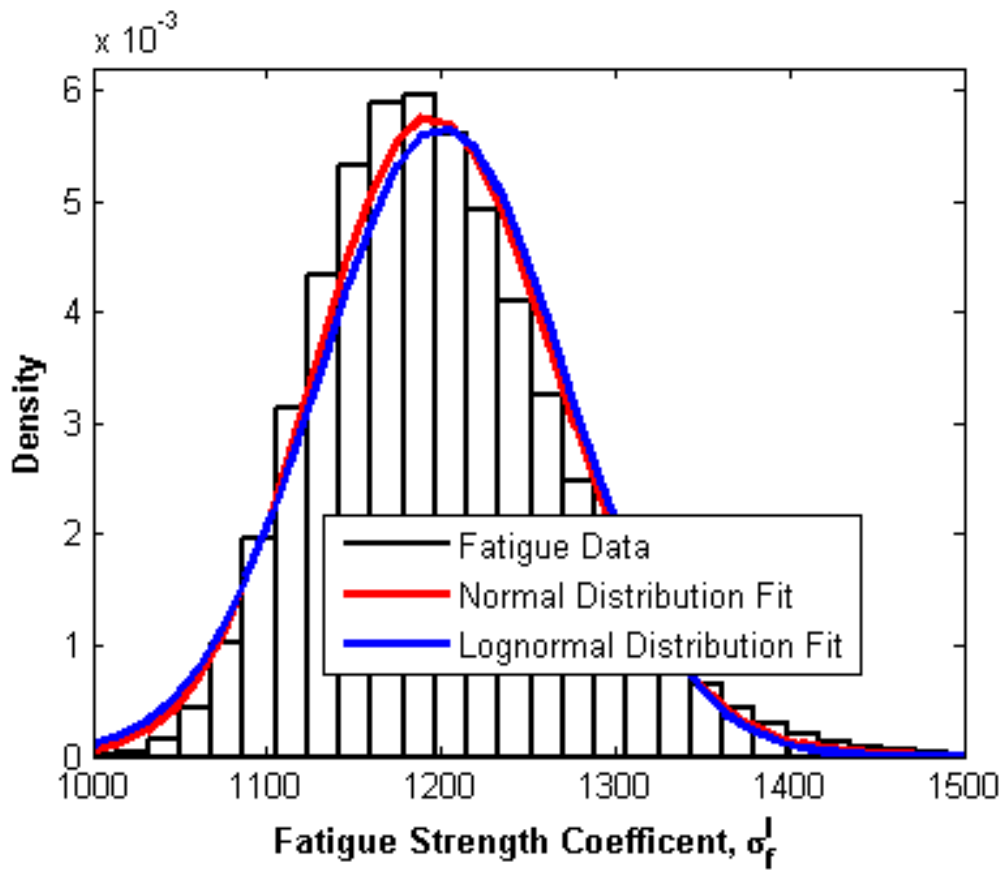

Figure 13a

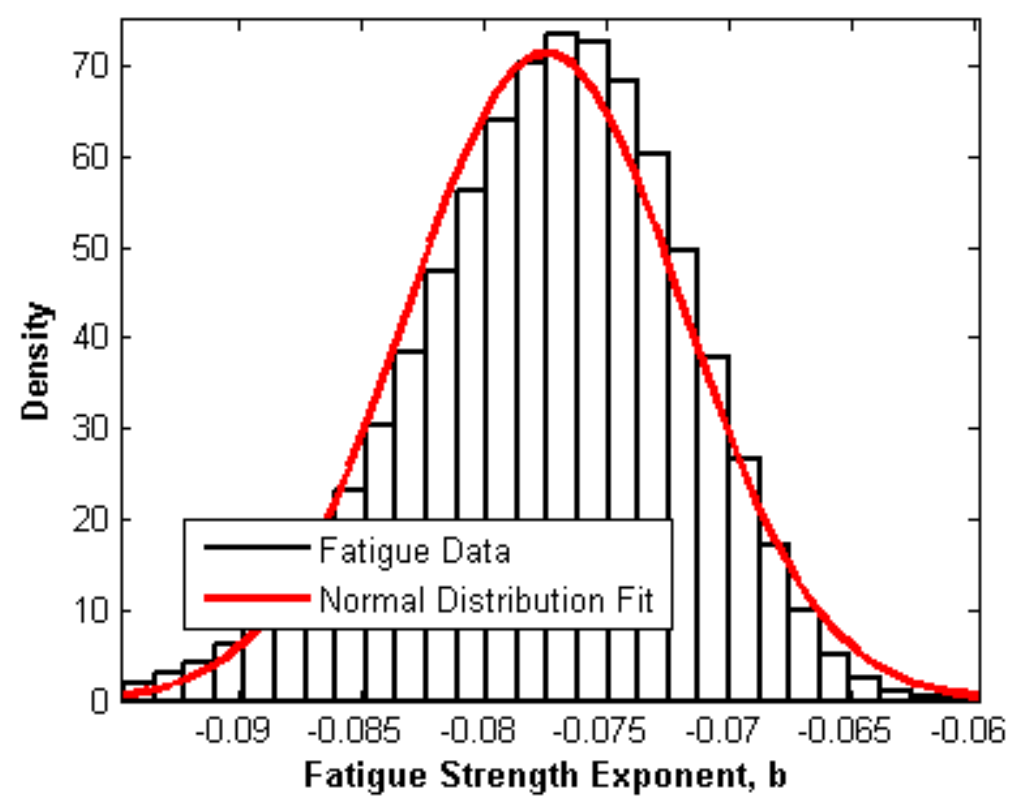

Figure 13b

Figure 13 : Distribution plot of a) fatigue strength coefficient and b) exponent values 


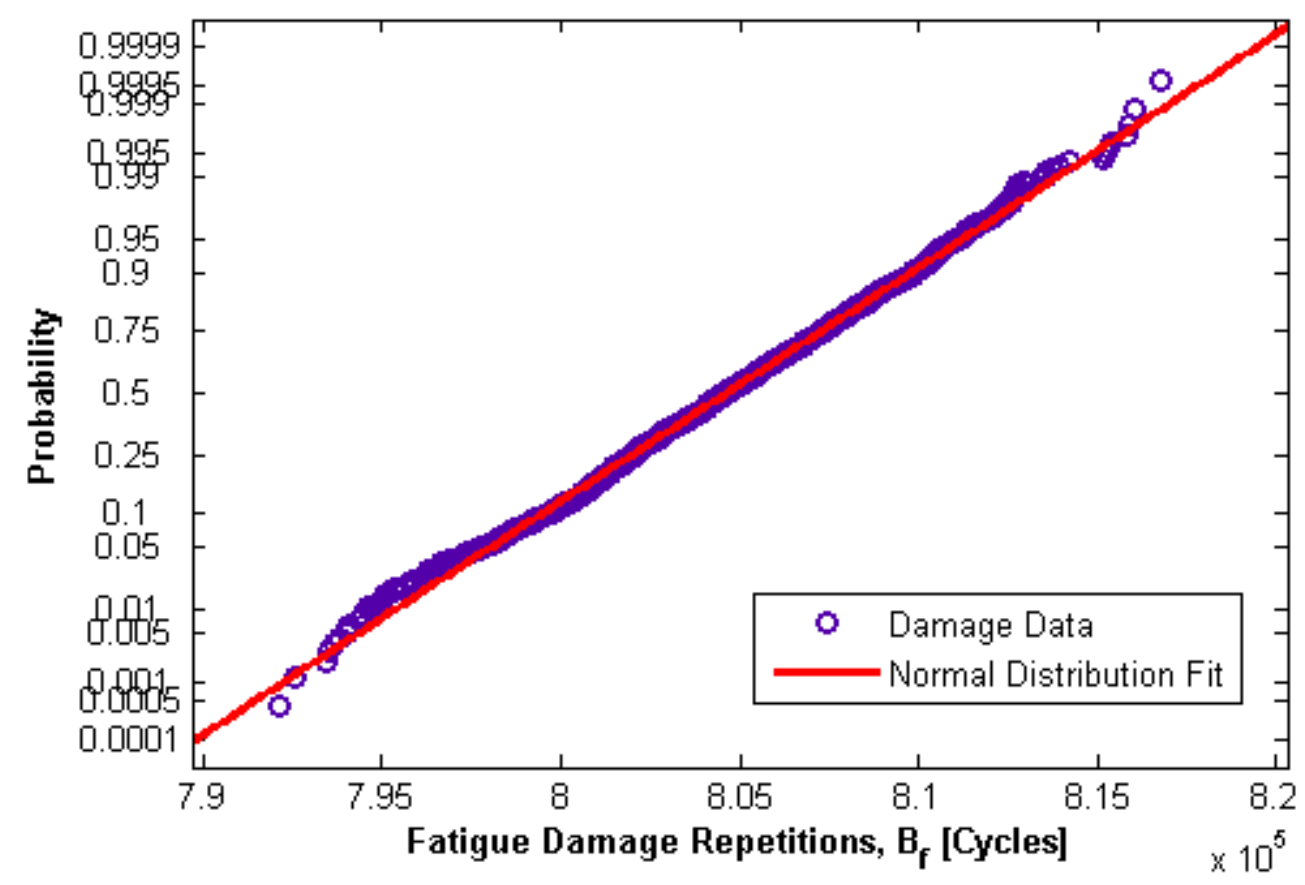

Figure 14 : Probability plot of fatigue damage repetitions

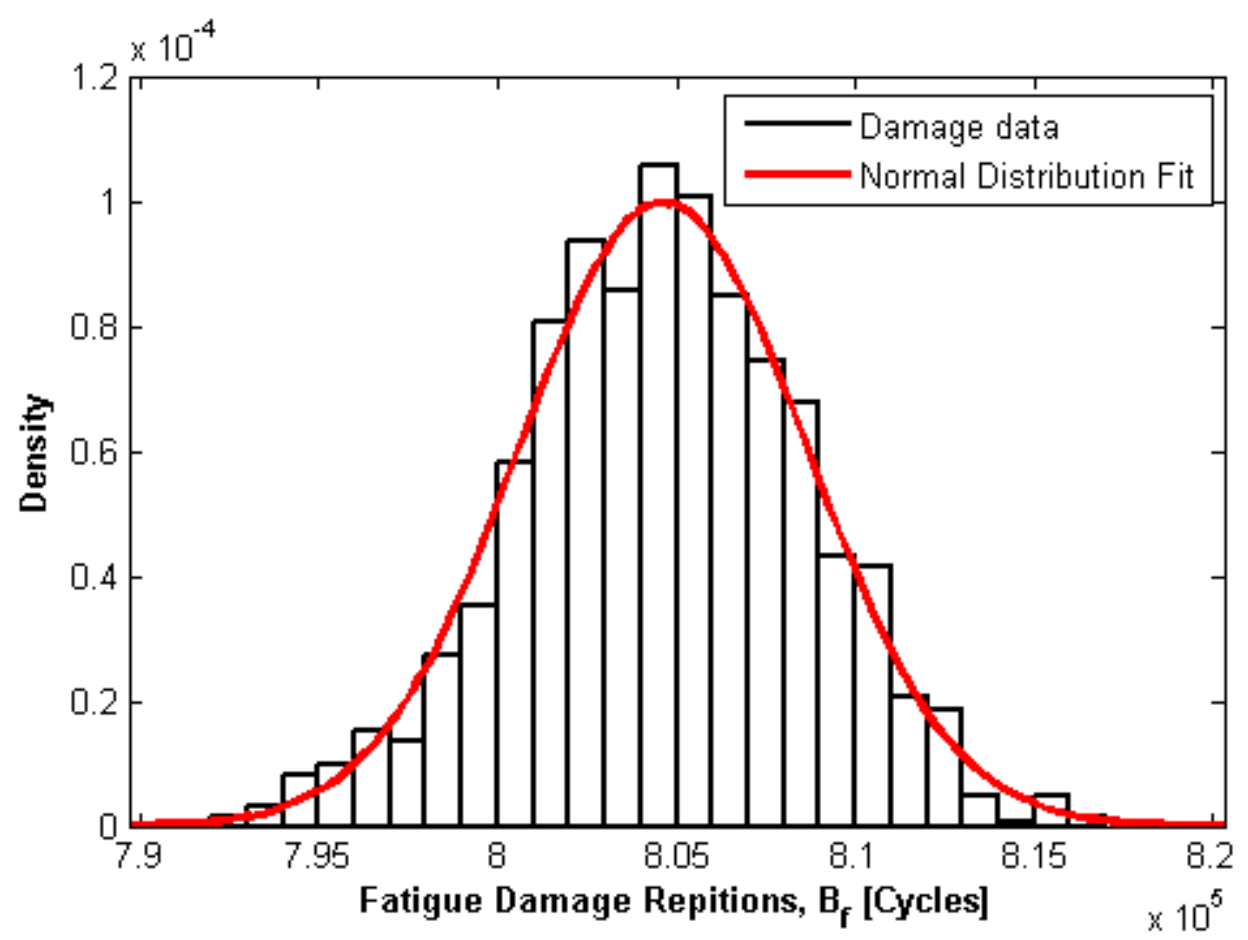

Figure 15 : Histogram summary of probabilistic fatigue damage repetitions 
Table 4: Probabilistic and discrete life model comparison

\begin{tabular}{lcc}
\hline Fatigue life model & \multicolumn{2}{c}{ Fatigue life results } \\
\cline { 2 - 3 } & Mean, $\mu$ & Std. Dev, $\sigma$ \\
\hline Probabilistic Model [repetitions] & $8.046 \times 10^{5}$ & 4000 \\
Discrete life model [repetitions] & $7.387 \times 10^{5}$ & - \\
Percentage difference [\%] & 8.98 & - \\
\hline
\end{tabular}

\section{Conclusions}

In this paper, the fatigue life of a low pressure steam turbine blade during simulated transient resonance conditions has been successfully assessed using a proposed probabilistic life model. Inputs into the life model have been established from numerical simulation of a last stage LP blade using FEM and experimental analysis of original blade material. Accuracy of the numerical model required validation which was performed using full scale spin testing frequency data and correlation with metallurgical findings. The use of a Campbell diagram developed from calculated and measured frequencies proved to be essential in ensuring the position of resonant excitation could be accurately established.

For turbine blades experiencing resonance at start-up conditions, slight variations in factors such as the steady state-mean stress, damping ratio, pressure excitation amplitude and the frequency of the fundamental mode of vibration were shown to influence the fatigue life results. Accounting for variability and uncertainty in some of these parameters, including the material fatigue properties, required random variable selection based on random variable curve fitting. This enabled all test and numerical data points to be used simultaneously and the variation estimated over the entire range of these points. Based on the random variable simulation results, by defining appropriate probability density functions, the statistics of the random variables could be accurately described. Overall the probabilistic fatigue life model was shown to be less conservative in predicting the life of the blade as calculations are based on nominal failure. The results were also shown to reinforce those of the discrete life model.

\section{References}

[1] EPRI. (1985). Survey of steam turbine blade failures. EPRI, Palo Alto, CA: CS-3891. 
[2] Rieger, N. F. (1988). The diagnosis and correction of steam turbine blade problems. In N. F. Rieger (Ed.), Rotordynamics 2: Problems in Turbomachinery. Italy: International Centre for Mechanical Sciences, 453-483.

[3] McCloskey, T. H. (2002). Troubleshooting turbine steam path damage mechanisms. In Proceedings of the thirty-first turbomachinery symposium, 105-144.

[4] Mukhopadhyay, N. K., Ghosh Chowdhury, S., Das, G., Chattoraj, I., Das, S. K., Bhattacharya, D. K. (1998). An Investigation of the Failure of Low Pressure Steam Turbine Blades. Engineering Failure Analysis, 5(3), 181-193.

[5] Wang, W.-Z., Xuan, F.-Z., Zhu, K.-L., Tu, S.-T. (2007). Failure analysis of the final stage blade in steam turbine. Engineering Failure Analysis, 14(4), 632-641.

[6] Mazur, Z., García-Illescas, R., Porcayo-Calderón, J. (2009). Last stage blades failure analysis of a 28MW geothermal turbine. Engineering Failure Analysis, 16(4), 1020-1032.

[7] Kim, H. (2011). Crack evaluation of the fourth stage blade in a low-pressure steam turbine. Engineering Failure Analysis, 18(3), 907-913.

[8] Rao, J S. (1998). Application of fracture mechanics in the failure analysis of a last stage steam turbine blade. Mechanism and Machine Theory, 33(5), 599-609.

[9] Rao, J S, Vyas, N. S. (1996). Determination of blade stresses under constant speed and transient conditions with nonlinear damping. Journal of Engineering for Gas Turbines and Power, $118(2), 424-433$.

[10] Szwedowicz, J., Visser, R., Sextro, W., Masserey, P. A. (2008). On nonlinear forced vibration of shrouded turbine blades. Journal of the American Statistical Association, 130, 1-9.

[11] Rao, J.S, Saldanha, A. (2003). Turbomachine blade damping. Journal of Sound and Vibration, 262(3), 731-738.

[12] Rao, J S, Gupta, K., Vyas, N. S. (1986). Blade damping measurements in a spin rig with nozzle passing excitation simulated by electromagnets. Shock Vib. Bull., 56(2), 109-116.

[13] Rieger, N. F. (1988). Damping properties of steam turbine blades. In N. F. Rieger (Ed.), Rotordynamics 2: Problems in Turbomachinery. Italy: International Centre for Mechanical Sciences, 515-541.

[14] Jaiswal, B.L., Bhave, S.K. (1994). Experimental evaluation of damping in a bladed disk model. Journal of Sound and Vibration, 177(1), 111-120.

[15] Rieger, N. F. (1988). An improved procedure for component life estimation with applications. In N. F. Rieger (Ed.), Rotordynamics 2: Problems in Turbomachinery. Italy: International Centre for Mechanical Sciences, 485-513

[16] Vyas, N. S., Rao, J. S. (1994). Fatigue life estimation procedure for a turbine blade under transient loads. Journal of Engineering for Gas Turbines and Power, 116(1), 198-206. 
[17] Chen, L., Liu, Y., Xie, L. (2007). Power-exponent function model for low-cycle fatigue life prediction and its applications - Part II: Life prediction of turbine blades under creep-fatigue interaction. International Journal of Fatigue, 29(1), 10-19.

[18] Shankar, M., Kumar, K., Ajit Prasad, S. L. (2010). T-root blades in a steam turbine rotor: A case study. Engineering Failure Analysis, 17(5), 1205-1212.

[19] Rao, J S, Pathak, A., Chawla, A. (2001). Blade life: A comparison by cumulative damage theories. Journal of Engineering for Gas Turbines and Power, 123(4), 886-892

[20] Shen, M. (1999). Reliability assessment of high cycle fatigue design of gas turbine blades using the probabilistic Goodman Diagram. International Journal of Fatigue, 21(7), 699-708.

[21] Liu, Y., Mahadevan, S. (2007). Stochastic fatigue damage modeling under variable amplitude loading. International Journal of Fatigue, 29, 1149-1161.

[22] Zhang, D., Hong, J., Ma, Y., Chen, L. (2011). A probability method for prediction on High Cycle Fatigue of blades caused by aerodynamic loads. Advances in Engineering Software, 42(12), 1059-1073Shen, H., Lin, J., Mu, E. (2000). Probabilistic model on stochastic fatigue damage $\dddot{i}$. International Journal of Fatigue, 22, 569-572.

[23] BSI. (2001). BS EN 10002-1:2001: Metallic materials - Tensile testing - Part 1: Method of test at ambient temperature. British Standards Institution, London, UK.

[24] ASTM. (2007). E 466: Standard practice for conducting force controlled constant amplitude axial fatigue tests of metallic materials. American Society for Testing and Materials, Philadelphia, USA.

[25] ASTM. (2010). E 739: Standard practice for statistical analysis of linear or linearized stress-life $(\mathrm{S}-\mathrm{N})$ and strain-life $(\varepsilon-\mathrm{N})$ fatigue data. American Society for Testing and Materials, Philadelphia, USA.

[26] EPRI. (2008). Steam turbine blade failure root cause analysis guide. EPRI, Palo Alto, CA: 1014137.

[27] Nieslony, A. (2009). Determination of fragments of multiaxial service loading strongly influencing the fatigue of machine components. Mechanical Systems and Signal Processing, 23(8), 2712-2721.

[28] Dowling, N.E. (2007). Mechanical behavior of materials: Engineering methods for deformation, fracture, and fatigue, 4th Edition, Pearson.

[29] Hong, C., Lam, T.C., Hesler, S.H. (1992). Steady and nonsteady steam bending force analysis and its application to blade life assessment. Proceedings of the EPRI Steam turbine and Generator NDE Life assessment and Maintenance workshop, Charlotte, NC, 43-1 - 43-18.

[30] Mathworks (n.d). Multivariate-normal-distribution, viewed 16 January 2014, from http://www.mathworks.com/help/stats/multivariate-normal-distribution.html

[31] Xiong, J.J., Shenoi, R.A. (2011). Fatigue and Fracture Reliability Engineering. Springer London. 